\title{
A internação compulsória e suas variáveis: reflexões éticas e socioculturais no tratamento e reinserção do paciente na sociedade
}

\author{
Compulsory internment and its variables: socio-cultural and ethical reflections on the \\ patient's treatment and reintegration into society \\ Internación obligatoria y sus variables: reflexiones socio-culturales y éticas en el \\ tratamiento del paciente y la reinserción en la sociedad \\ Viviana Rosa Reguera Ruiz \\ Heitor Romero Marques ${ }^{1}$ \\ Universidade Católica Dom Bosco-UCDB
}

\begin{abstract}
Resumo
A drogadição e suas consequências, após muitas tentativas de enfrentamento, ainda remetem um desafio quanto ao melhor tipo de tratamento a ser destinado aos dependentes químicos. A questão emerge perante a sociedade e não é possível solucionar somente com medidas paliativas. Este artigo pretende analisar as questões éticas e socioculturais interpostas na utilização da internação compulsória no tratamento da dependência química. Para tanto, o recurso utilizado foi de revisão bibliográfica para enfatizar a medida de intervenção obrigatória na saúde do drogodependente, reformulada pela Lei n. 10.216/01, por ser realizada sem a submissão do paciente. O artigo faz um breve apanhado histórico acerca das legislações que regulamentam as drogas desde o proibicionismo da segunda metade do século XX até a atual Lei n. 11.343/06. O artigo discute as responsabilidades de cada ente social, bem como a do próprio usuário de drogas frente a sua capacidade de decisão. Ademais, evidencia a necessidade da construção de estruturas adequadas para tratar da drogadição, elemento fundamental para a reinserção social. Palavras-chave: Internação compulsória; Dependência química; Drogas; Tratamento; Sociedade.
\end{abstract}

\begin{abstract}
The addiction and its consequences, after several attempts of combating, are still a challenge in a sense of the modalities of treatments destined to the chemically dependents. The question emerges in the society and it is not possible to solve it with palliative measures. This article aims to analyze the ethical and socio-cultural questions inserted in the use of the compulsory internment in order to treat the chemical dependence. Therefore, we have used, as the source of researching, a bibliographical revision to emphasize the measure of compulsory intervention in health of drug abusers, reformulated by the Law n. 10.216/01, which concerns about internment measure without the own patient's submission. This text involves a brief historical overview about the laws regulate drugs, from the prohibition in the second half of the 20th century to the current Brazilian law n. 11.343/06. This article also the responsibilities of some social entities, as well as the own users' drugs about their decision-making ability. Moreover, this text highlights the necessity to construct appropriate structures to treat with the drug addiction, which is a fundamental element for social reintegration.

Key-words: Compulsory internment; Chemical dependency; Drugs; Treatment; Society.
\end{abstract}

\begin{abstract}
Resumen
La drogadicción y sus consecuencias, después de años de evolución y tentativas de enfrentamiento, aún remiten a un reto con relación al mejor tipo de tratamiento a ser destinado a los dependientes químicos. La cuestión aparece en la sociedad y no es posible solucionar solamente con medidas paliativas. Ese artículo pretende analizar las cuestiones éticas e socio-culturales interpuestas en la utilización de la internación compulsoria en el tratamiento de la dependencia química. Para eso, el recurso utilizado fue la revisión bibliográfica para enfatizar la medida de intervención obligatoria en la salud del drogodependiente, reformulada por la Ley n. 10.216/01, por ser realizada sin permiso del paciente. La investigación hace uno breve apañado histórico de las normas que reglamentan las drogas desde la prohibición en la segunda mitad del siglo XX hasta la actual Ley n. 11.343/06. Propone una discusión de las responsabilidades de cada ente social, bien como del usuario de drogas frente a su capacidad de decisión. Además, evidencia la necesidad de construcción de estructuras adecuadas para tratar de la drogadicción, elemento fundamental para la reinserción social.
\end{abstract}

Palabras-clave: Internación obligatoria; Dependencia de sustancias químicas; Drogas; Tratamiento; Sociedad.

\section{Introdução}

A discussão sobre o tratamento dispensado às

Endereço 1: Endereço para Correspondência: Av. Tamandaré, 6000 Jd Seminário. CEP 79117900. drogas sofreu modificações em todo o mundo desde que seu consumo, fabricação e comercialização, começaram a ser restringidos. O proibicionismo, tão proclamado desde os anos de 1920, significou por muito tempo o modelo oficial de combate às substâncias ilícitas.

Ao oposto do que almejava, a proibição não 
conseguiu romper com a proliferação das drogas no cenário mundial, e nem eliminar de vez sua utilização. Logo, com as consequências do vício, atingindo todas as camadas da sociedade, era preciso fazer alguma coisa, em reposta, surgiram as internações.

Consideradas simplesmente um modelo de exclusão, de reclusão e asilamento, as internações foram - até a o advento da Reforma Psiquiátrica, alvos de intensas críticas dos defensores dos direitos humanos, devido às denúncias de maus tratos e por constituírem apenas uma forma de recolhimento daqueles julgados como desajustados para conviver em sociedade.

Como afirmado acima, com a Reforma Psiquiátrica embasada pela Lei n.10.216/01, a dignidade e os direitos do paciente vieram à tona, por meio da regulamentação dos diversos serviços em assistência psiquiátrica, dentre estes, as internações voluntária, involuntária e compulsória.

O resultado desta reformulação contribuiu em muito para que o doente mental, neste artigo representado pela figura do dependente químico, fosse visto de forma humanizada. Entretanto, no debate sobre a melhor forma de tratamento da dependência, os tipos de internação, principalmente a compulsória, continuam a dividir opiniões. Pois, para alguns, a imposição da obrigatoriedade em saúde, serve tão somente para camuflar os problemas sociais, enquanto fere o direito de liberdade, para outros significa proteger a vida de acordo com a Constituição da Republica Federativa do Brasil de 1988 (BRASIL, 1988).

Dadas às circunstâncias, este artigo pretende analisar alguns pressupostos acerca da utilização da internação compulsória, tal como o envolvimento dos diversos órgãos da sociedade ante a problemática da dependência, a importância da participação e do apoio da família e o agravante do abandono e descaso, pois, tem-se a legislação preocupada em reforçar e restaurar os vínculos familiares, mas, e quantos aos desassistidos quem pode decidir por eles?

A pesquisa aqui relatada tem o intuito de discorrer sobre o tratamento obrigatório em dependência química, mais particularmente sobre a internação compulsória, para tanto optou-se pela revisão bibliográfica.

\section{Aspectos legais e de saúde acerca da dependência química}

Antes de entrar no mérito da internação compulsória e a possibilidade de sua utilização no tratamento da dependência química, faz-se necessária à compreensão da importância da Reforma Psiquiátrica. Num breve resumo, a referida norma representou um avanço no contexto da saúde mental, pois significou uma reformulação do modelo psiquiátrico até então vigente sob um histórico de recorrentes denúncias de violência e descaso aos direitos humanos.

A desinstitucionalização era o principal objetivo do movimento, juntamente com o resgate da cidadania e do respeito à singularidade e subjetividade do doente mental (Fortes, 2010). Em síntese, a Reforma Psiquiátrica contribuiu na mudança por dispor sobre os direitos do portador do transtorno mental, relacionar as obrigações do Estado, definir e regulamentar os tipos de internações, tratar das pesquisas envolvendo esses pacientes e colocar a encargo do Conselho Nacional de Saúde, a criação da Comissão Nacional para o acompanhamento da implementação da lei.

As disposições acima estão presentes no corpo da Lei n. 10.216 de 06 de abril de 2001, de proposição do Senador Sebastião Rocha, composta por 13 artigos, os quais prezam a questão de proteção do portador de transtorno mental e o redirecionamento do modelo assistencial, a extinção dos manicômios e a regulamentação da internação psiquiátrica compulsória.

Nesse sentido, a dependência decorrente do uso de substâncias psicoativas encontra respaldo nesta legislação, pois, de acordo com Freitas (2010) ela é considerada uma síndrome, apresenta um quadro clínico, e está classificada no Código Internacional de Doenças ( CID) e no Manual Estatístico de Doenças (DSM), sendo portanto, entendida como um transtorno mental passível de alterações no funcionamento mental, determinantes para prejudicar o desempenho do individuo globalmente.

\section{Tratamento obrigatório: principais critérios para sua ocorrência}

A redação da Lei n. 10.216/2001 prevê como recurso de tratamento a internação compulsória, conforme estabelecido no artigo $6^{\circ}$, Inciso III: "internação compulsória: aquela determinada pela Justiça". Nos termos do artigo $9^{\circ}$, é determinado que este instituto deve ser indicado impreterivelmente por um juiz competente, ficando a seu critério considerar as condições de segurança do estabelecimento, no sentido de salvaguardar a integridade do paciente, dos demais internados e funcionários.

De acordo com a legislação citada, a internação involuntária - e voluntária neste caso, deve obedecer alguns critérios para sua ocasião, conformedeterminada no artigo $8^{\circ}$, "será autorizada por médico devidamente registrado no Conselho Regional de Medicina (CRM) do Estado onde se localize o estabelecimento" (Brasil, 2001) e, no primeiro parágrafo fica estipulado que a ocorrência da internação bem como a sua alta devem ser comunicadas ao Ministério Público Estadual, no devido prazo de setenta e duas horas.

Para Quevedo, Schmitt e Kapczinski (as cited in Maciel, 2013), a Internação Involuntária deve preencher alguns critérios: A e B:

A - Doença mental, exceto transtorno de 
personalidade antissocial.

B - No mínimo um dos seguintes: Risco de autoagressão; Risco de heteroagressão; Risco de agressão à ordem pública; Risco de exposição social; Incapacidade grave de autocuidados.

O professor e doutor Ileno Izídio da Costa (2013) é categórico ao afirmar que a internação compulsória, verdadeiramente aceita para o âmbito jurídico, é aquela determinada nos casos de processos criminais, na qual o réu sofre medida de segurança, com base em relatório médico-pericial e sob a existência de riscos para o paciente e terceiros. No segundo parágrafo do mesmo artigo, o término da internação involuntária é definido por meio de solicitação formal do familiar ou, responsável legal do internando.

Nesse sentido, a Lei de 2001 aborda "a universalidade de acesso e direito a assistência, valorizando a territorialização do atendimento, edificando redes assistenciais com vistas à reinserção social e ressocialização dos usuários" (Pinho as cited in Correia \& Ventura, 2013). Não obstante, é possível perceber que as propostas de intervenção foram trabalhadas de forma genérica, empobrecidas de orientações e procedimentos necessários e em colisão com uma realidade, na qual se sabe da inexistência de uma rede extra-hospitalar ampla e eficiente (Pinheiro, 2012).

\section{A lei antidrogas: uma proposta de redução de danos}

Até meados do ano de 2003, conforme explicam Correia e Ventura (2013), dois diplomas legais, a Lei $\mathrm{n}^{\circ} 6.368$, de 21 de outubro de 1976 - conhecida como lei antitóxicos e, sua substituta a Lei $\mathrm{n}^{\circ} 10.409$ de 2002, eram as normas responsáveis por regulamentar os aspectos relacionados às drogas, seguindo o viés proibicionista.

Após esse período, diversas alterações ocorrem com intuito de priorizar a dignidade humana e derrubar este panorama de controle repressor. Tem inicio os projetos visando à redução de danos ao invés de redução de oferta. Nesse sentido, foi criada a Lei n. 11.343/2006 que instituiu o Sistema Nacional de Políticas Públicas sobre Drogas (Sisnad) com objetivos, conforme descritos no texto da legislação de articulação, integração, organização e coordenação das atividades de prevenção, tratamento e reinserção social de usuários e dependentes de drogas (Secretaria Nacional de Políticas sobre Drogas [Senad], 2010).

Essa perspectiva com enfoque na diminuição dos riscos trabalha com a questão de liberdade e o modelo pode ser traduzido como o que "defende o direito de escolhas individuais, livres de qualquer imposição do Estado ou de outras instituições" (Alessandra Diehl et al. as cited in França, 2012). Ainda segundo a Equipe Médica da Unidade de Psiquiatria de Adição do Hospital de Clínicas de Porto Alegre (Instituto
Crack Nem pensar, 2014) a redução de danos pode ser entendida como:

[...] uma das modalidades de tratamento usadas principalmente para prevenir complicações maiores relacionadas ao uso de drogas naqueles usuários que não desejam a abstinência total. Foi desenvolvida na Inglaterra, em 1920, para abordar usuários de heroína e foi sendo modificada ao longo dos anos. Alguns dos exemplos de estratégias são: distribuição de seringas para usuários de drogas injetáveis; distribuição de preservativos; distribuição de cachimbos a usuários de crack, a fim de reduzir a disseminação de doenças infecciosas.

Diretrizes como as destacadas anteriormente, são bases do programa intitulado "Crack, é possível vencer", do Governo Federal, lançado em 2011, referência atual no Brasil em termos de enfrentamento e tratamento da drogadição, cujas metas, presentes numa cartilha de mesmo nome do programa, têm por prazo até o final do ano de 2014, a ampliação de redes de atendimento e atenção em saúde, o fortalecimento da prevenção e da assistência social aos usuários de drogas entre outros (Portal Brasil, 2013).

A entrada da Lei n.11.343/06, de acordo com alguns estudiosos, serviu para abrandar a punição ao usuário de entorpecente e agravar a situação penal dos traficantes e agentes responsáveis pela disseminação de substâncias ilícitas. Tal legislação distanciou em termos legais o que faz uso de drogas ocasionalmente ou esporadicamente com aquele que comercializa, a diferenciação entre ambos lançou novas concepções de intervenções, com a inserção de medidas educativas e exclusão da pena privativa de liberdade, não dispondo de qualquer previsão de internação de usuários. No entanto, essa lei continua a criminalizar a conduta, o que gera diversas controvérsias a respeito de sua eficácia, pois, o doente necessita de tratamento e não de punição (França, 2012). Essas penas podem ser observadas no artigo 28 da citada lei (Brasil, 2006), como segue:

I - advertência sobre os efeitos das drogas;

II - prestação de serviços à comunidade;

III - medida educativa de comparecimento a programa ou curso educativo.

Nesse aspecto, Correia Júnior e Ventura (2013) se apropriam da afirmação de que a Lei n. 11.343/06, conhecida como Antidrogas é paradoxal, pois em parte se mostra sensível à questão da redução de danos, com vários artigos enfatizando a relação das políticas públicas de drogas com a saúde pública, assim como a inclusão do sujeito, respeitando sua autonomia e vontade, mas, por outro lado a partir do artigo 33, volta a legitimar a política repressiva e bélica do combate às drogas.

Sem aprofundar no mérito das principais falibilidades encontradas na Lei, apontadas em pesquisas e, retomando o contexto da internação compulsória, para Correia Junior e Ventura (2013), as consequências de não se permitir a coerção do 
individuo a um tratamento ou intervenção médica, faz com que as autoridades fiquem limitadas em seu poder repressivo e preventivo, pois não podem ir além do que a norma autoriza. E, admoestações e advertências, por si só, como garantidas na Lei n. 11.343/06, não só desgastam o trabalho do judiciário e sua equipe, como o usuário em seu ciclo de vício, prevendo a impunidade, não será somente uma vez surpreendido se drogando.

Diante de tais afirmações, denota-se que, em sintonia com os objetivos da referida legislação, de atenção e reinserção do usuário, é inquestionável sua importância na fomentação de diversos programas em todo o Brasil, considerando outros meios de encarar a drogadição, sem somente recorrer à institucionalização, mas a outros eixos, como o cuidado, prevenção e autoridade.

\section{Do direito à autonomia da escolha}

A utilização da internação compulsória (por ordem judicial) ou involuntária (por ordem médica e sem o consentimento do internando), como estratégia no tratamento da dependência química, alçou um patamar de tabu perante a sociedade, pois, quando se trata desta modalidade de intervenção, seja para o combate às drogas ou qualquer outra finalidade, observa-se um paradoxo em sua fundamentação, na qual é configurada para proteger o individuo de danos que possa oferecer a si próprio e a outrem (Costa, 2012), bem como possibilitar um meio de acesso aos serviços de saúde, mas, é criticada por indicar punição ao invés de tratamento e ferir o direito de liberdade, o de ir e vir (Scisleski \& Maraschin, 2008).

A efetivação de um tratamento obrigatório dentre as diretrizes que envolvem esforços para controlar o uso e o tráfico ilícito de drogas, neste trabalho representado pelo instituto da internação compulsória, tropeça no questionamento acerca da autonomia do paciente, no que tange ao reconhecimento intrapessoal deste individuo da necessidade de se obter ajuda. Defende-se a prerrogativa, na qual a crença por parte do paciente, na mudança de comportamentos relacionados à dependência química seja fundamental no sucesso no tratamento (Bortolon, Fernandes, Moreira \& Signor, 2013).

Segundo o Guia para a Família, publicado pela Secretaria Nacional de Políticas sobre Drogas (Silveira \& Silveira, 1999), a violação do direito a escolha e a institucionalização não consensual, pode ser insatisfatória, resultando inclusive num efeito oposto, ou seja, no aumento do consumo de substâncias ilícitas e por conseguintes outros problemas conhecidos, tais como reafirmar a organização do tráfico, à violência e criminalidade.

Dessa forma, ao mesmo tempo em que o Principio da Legalidade garante no artigo $5^{\circ}$, inciso II da Constituição Federal (1988) que "ninguém será obrigado a fazer ou deixar de fazer alguma coisa senão em virtude de lei”, permanece a questão sobre a capacidade de discernimento do drogodependente, pois, considerando as variações individuais de vício, sabe-se que o individuo se encontra numa situação, de autonomia reduzida, sob constante influência das drogas (Takahashi, 2009).

A iniciativa da submissão voluntária ao tratamento por parte do dependente, por diversas vezes não se concretiza devido à presença de sintomas compulsivos característicos do abuso destas substâncias psicoativas, essas alterações decorrentes de uma ingestão contínua são classificadas como cognitivas, comportamentais e fisiológicas. Conforme explica Ballone (2013), a existência de um ciclo de consumo repetitivo favorece o estabelecimento de três fatores normativos da dependência: tolerância, abstinência e compulsão.

Seguindo tal pensamento, o deputado federal Osmar Terra (as cited in Correia Junior e Ventura, 2013) argumenta que "aquele que está intoxicado não tem a capacidade de discernir o que é certo do que é errado, pois as drogas, a exemplo do crack, comprometem o funcionamento do cérebro". Reitera ainda que o uso desencadeia um estado irracional, provocado pelo vicio, no qual o individuo vende todos os seus bens, envolve-se em brigas com amigos e familiares, passa a dormir no relento, alimenta-se precariamente e não consegue estabelecer qualquer compromisso com trabalho e estudo.

\section{Relações sociais}

Sabe-se que o uso compulsivo de substâncias ilícitas, após desestabilizar o indivíduo, provoca a ruptura dos laços de convivência e vínculos afetivos outrora firmados, este enfraquecimento qualitativo e quantitativo da rede social do dependente químico interfere, na concepção de Pinho (2009), desde a primeira relação social disponível que é o núcleo familiar.

As demandas apresentadas por estes familiares afetados pelas consequências do vício são das mais variadas ordens, face a este problema, Colvero e outros (2004) destacam algumas, dentre elas, dificuldade para lidarem com as crises e conflitos emergentes, com a culpa, com o isolamento social a que ficam sujeitos e a desesperança, além do desgaste físico e emocional provocado por consequentes insucessos no relacionamento com o dependente químico, bem como pelo desconhecimento da doença propriamente dita, dentre tantas outras insatisfações.

Desta forma, a família não deve ficar à margem dos conflitos relacionados às drogas e, deve receber atenção especial no que tange a elaboração de políticas e programas sociais que atendam os contornos e suas especificidades, tanto nas questões materiais e financeiras, quanto no que se refere aos problemas 
cotidianos estabelecidos em suas relações sociais (Goulart, Soares, Machado \& Shera, 2013).

Portanto, a compreensão desses aspectos é fundamental no sentido de se discutir quais as estratégias de intervenções eficazes e coerentes, em sintonia com a posição do dependente químico na atualidade e a forma de como a droga vem evoluindo ao longo dos anos. Assim, na concepção de Pratta e Santos (2009) é correto afirmar que a drogadição, progrediu em conjunto com as culturas, com os padrões, a frequência de utilização e os tipos de drogas consumidos mudam de uma época para outra de acordo com as condições socioculturais existentes.

Diante do exposto, percebeu-se ao falar sobre internação compulsória ou involuntária que, não é um assunto simples do qual todos os estudiosos concordam quanto às formas de lidar, uma vez que a dependência química começou a ser trabalhada sob outra ótica, principalmente no final do século $\mathrm{XX}$, novas abordagens a respeito do usuário ou do dependente ganharam força contra as de cunho assistencialistas psiquiátricas (Pratta \& Santos, 2009). Justamente porque a droga tornou-se mais que um problema social, contribuindo diretamente para o aumento dos índices de criminalidade em todos os estados brasileiros (Dias, 2012). Como bem salientado por Araújo (2000, p. 102), esses sujeitos formam um grupo vulnerável a estigmatização e a exclusão, devido à estreita correlação entre estar nas ruas e usar drogas, ser vítima e estar sujeito à violência.

\section{Drogodependente e criminoso}

Durante três décadas, o que se observou em termos enfrentamento às drogas, conforme explicam Correia Júnior e Ventura (2013), era uma notória guerra declarada às substâncias, sob o prisma de associação entre o dependente químico e o criminoso, de estigmatização do uso e a institucionalização relegada ao papel de protagonista, enquanto a saúde e o devido tratamento para a dependência ficavam num segundo plano, sem a merecida atenção. Os discursos políticos e midiáticos, de caráter imediatista, utilizam da internação como artifício de repressão e controle, por julgarem mais eficazes e significativos na intenção de demonstrar agilidade, sem considerar o uso da droga como um sintoma social carente de inclusão e responsabilidade conjunta (Correia Junior e Ventura, 2013).

No entanto, privilegiar este recurso na forma de tratar o drogodependente, justificado apenas pela necessidade de um controle sobre os riscos sociais decorrentes da dependência e sem considerar a que droga se está referindo, ou em que contextos esta drogadição se estabeleceu, é eximir da responsabilidade outros atores fundamentais do contexto: a família, a comunidade e o próprio estado (Costa, 2013).
Há uma escassez de estudos publicados acerca de quais ações são pertinentes ao perfil de dependente químico que, depois de muitos anos como usuário de drogas, está sozinho nas ruas, abandonado à própria sorte, sem a possibilidade do cuidado sócio-familiar em seu tratamento, já que esta estrutura de apoio é ineficiente ou devido às circunstâncias inexistentes. Então essa massa de desassistidos, impõe ao Estado alguma atitude, em observância do artigo 196 da Constituição de 1988 (1988):

A saúde é direito de todos e dever do Estado, garantido mediante políticas sociais e econômicas que visem à redução do risco de doença e de outros agravos e ao acesso universal e igualitário às ações e serviços para sua promoção, proteção e recuperação.

Como consequência, na maioria dos casos, a internação compulsória acaba por ser o primeiro recurso utilizado. Observado o artigo 227 da Constituição, o qual determina a responsabilidade da família, da sociedade e do Estado na promoção de oportunidades à vida e à saúde, Rodrigues (2012) salienta ser pertinente e legal a sua utilização em atendimento ao texto constitucional mencionado.

Por mais divergentes que sejam as opiniões sobre qual a melhor maneira de lidar com o avanço da drogadição e seu tratamento, há uma concordância geral de que alguma intervenção terapêutica deve ser elencada no lugar da negligência e da omissão. Nesse sentido, Costa (2012) aponta uma grande falha do instituto da internação compulsória, a recaída. Segundo a autora, por ser uma medida que depende efetivamente do querer do paciente, observa-se altas taxas de reincidência nos usuários submetidos. Assim também argumenta Castilho (2012) que na vertente da internação não é incomum a situação de recidiva, o que a torna desfavorável, pois, gera novos e sucessivos recolhimentos forçados.

Nesse sentido, respeitadas as singularidades de cada individuo, é recomendável que a partir do acolhimento seja iniciado um acompanhamento, a fim de que sejam identificadas precocemente as possíveis dificuldades do dependente na adesão ao tratamento e a formulação e elaboração do projeto terapêutico tenham maior eficácia (Silva, 2013).

Alguns estudos sugerem diversas práticas quanto ao cuidado relacionado à recaída, dentre elas a associação com uma religião, independente de qual seja, é indicada como facilitadora da recuperação da dependência e está relacionada a um menor consumo de drogas, para tanto, o usuário deve recorrer a orações nos momentos de abstinência (Sanchez \& Nappo, 2008). Observa-se que esta intervenção baseada nos princípios de religiosidade próprios de cada grupo, propõe a reclusão do drogodependente em instalações, na sua maioria, rurais de difícil acesso.

Essas unidades de tratamento são conhecidas como comunidades terapêuticas e, de acordo com George de Leon (2003) "surgiram em 1979. Possuem registros 
necessários para funcionamento e não podem executar o tratamento involuntário, ou seja, elas não podem fazer a remoção do paciente e levá-lo para a clinica". Ao contrário desta afirmação, a realidade dessas comunidades evidencia um sistema de funcionamento e de regras que remetem à internação involuntária, assim como foi exposto no relatório proposto pela Comissão Nacional de Direitos Humanos do Conselho Federal de Psicologia, denominada como $4^{\mathrm{a}}$ Inspeção Nacional de Direitos Humanos: locais de internação para usuários de drogas (CFP, 2011, p. 190):

Há claros indícios de violação de direitos humanos em todos os relatos. De forma acintosa ou sutil, esta prática social tem como pilar a banalização dos direitos dos internos. Exemplificando a afirmativa, registramos: interceptação e violação de correspondências, violência física, castigos, torturas, exposição a situações de humilhação, imposição de credo, exigência de exames clínicos, como o teste de HIV - exigência esta inconstitucional -, intimidações, desrespeito à orientação sexual, revista vexatória de familiares, violação de privacidade, entre outras, são ocorrências registradas em todos os lugares.

$\mathrm{Na}$ lógica dos serviços oferecidos por essas comunidades, baseadas numa promoção de desintoxicação total por meio da exposição às violentas crises de abstinência em sua maioria sem o devido acompanhamento de um profissional, "o sujeito é mais que passivo, ele é convertido em objeto sobre o qual recai a ação definida por terceiros" (Vargas, 2012).

Frente a essa situação, pode-se compreender que a internação, apenas com o objetivo de retirar o sujeito das ruas, ainda que em sua essência promovida com "boas intenções", sem o trabalho de uma equipe multidisciplinar especializada em dependência química, carente de fiscalização e métodos flexíveis, não simboliza um tratamento, mas sim uma medida crua de repressão e reclusão.

\section{Considerações Finais}

Neste estudo buscou-se fazer uma reflexão acerca da proposta da internação compulsória, em virtude da problemática relacionada ao consumo e ao comércio de drogas, não ter retrocedido em todos esses anos de enfrentamento, apesar das alterações jurídicas e sociais. De acordo com o Escritório das Nações Unidas sobre Drogas e Crime a prevalência do uso de substâncias ilícitas no mundo é estável. Portanto, é possível perceber quão equivocada é a ideologia de acabar de vez com as drogas, uma vez que seu uso pode estar atrelado a questões socioculturais e geográficas.

O objetivo traçado foi o de analisar, por meio de pressupostos teóricos, como a internação compulsória e a involuntária, ambas aplicadas sem levar em conta a vontade do paciente, podem coexistir em conjunto com a nova posição do drogodependente no cenário mundial e em harmonia com a reformulação da assistência psiquiátrica, introduzida pela Lei n. 10.216 de 2001.

Essa legislação foi responsável por trazer um tratamento mais humano aos pacientes, em consonância com os direitos humanos, no campo da cidadania e da inclusão. Seu objetivo foi o de romper com o longo histórico de internações compulsórias de doentes mentais, acompanhadas do registro de denúncias terríveis acerca de maus tratos, superlotação, mortes, permanências vitalícias em manicômios e similares. A lei também definiu os tipos de internação: voluntária, involuntária e compulsória e, regulamentou os critérios de sua ocorrência.

A partir do desenvolvimento da pesquisa, foi possível constatar a existência de uma preocupação em todas as esferas da sociedade no que tange às drogas, entretanto, há de se concordar que o Brasil não possui estrutura equivalente as apresentadas na redação da Lei n.10.216 de 2001, sendo que esta deixou a desejar em orientações e roteiros para execução de suas propostas. Evidentemente houve um avanço, mas este tem acontecido a passos curtos.

A internação foi criada para intervir na crise, especificamente quando o individuo estiver colocando em risco a sua vida e a de outras pessoas. Não são encontradas ressalvas quando se refere à internação voluntaria, porém, é amplamente questionável a aplicabilidade dos tratamentos obrigatórios ao dependente químico. As criticas são por conta do paradoxo que apresentam, por um ângulo intentam proteger a vida, mas, por outro constituem violação da liberdade e punição.

Sobre esses aspectos, foi discutida a capacidade do drogodependente em decidir ou não sobre a intervenção de terceiros em sua saúde. O querer, para alguns autores citados se revela quesito fundamental no sucesso do tratamento. Entretanto, o discernimento pode estar comprometido, por diversos fatores, oriundos do uso continuo, sendo os efeitos próprios das substâncias no organismo e suas consequências na vida do sujeito.

Diante do exposto, o conhecimento prévio das substâncias garante uma intervenção apropriada a cada caso. Além de contribuir para mudar o paradigma, no qual o dependente químico é apenas um marginal que incomoda por oferecer perigo e, por isso deve ser afastado do convívio com os demais.

O estereótipo construído em torno do usuário de drogas favorece a ruptura dos vínculos, já que o medo, vergonha e o fato não saber lidar com a drogadição faz com que a rede social do individuo procure responsabilizar terceiros pelo vício e, na maioria das vezes os abandone a própria sorte. Concluiu-se que nem o drogodependente e nem outro ente deve ser responsabilizado sozinho pela questão das drogas. A dependência química surge de um conjunto de fatores 
não isolados.

Para reunir todos os setores da sociedade em prol do enfrentamento às drogas, tem-se a nova proposta de redução de danos, ampliada e fixada por intermédio da Lei n. 11.343/06. Este diploma legal diferenciou o usuário do traficante, traçou aplicações penais a determinadas condutas e tem sido importante na discussão da inserção do usuário na sociedade. Entretanto, não concilia internação em nenhuma de suas propostas, o que é falível segundo diversas linhas de pensamento.

Por fim, este estudo entende que a aplicabilidade da internação compulsória, só é possível, se acompanhada do monitoramento de uma equipe multidisciplinar capacitada, pronta a respeitar os variados níveis de dependência e os direitos constitucionais do paciente. Integrada a outras propostas de intervenção, mediante locais adequados e fiscalizações permanentes.

\section{Referências}

Araujo, C. H. (2000). No Meio da Rua: Migrações e vidas nas ruas. Rio de Janeiro, Brasil: Garamond.

Ballone, GJ. (n.d.). A internação compulsória é, de fato, um recurso extremo. Às vezes inevitável. Recuperado em 11 Setembro, 2013, de http://www.psiqweb.med.br/site/?area=NO/ LerNoticia\&idNoticia $=352$

Bortolon, C. B., Fernandes, S., Moreira, T. DE C., \& Signor, L. (2013). Abordagem Multidisciplinar da Dependência Química. São Paulo, Brasil: Santos.

Constituição da República Federativa do Brasil [Const]. Outubro 5 de 1988 (Brasil).

Câmara dos Deputados, 1989. Projeto de Lei 3.657 de 1989. Diário do Congresso Nacional. 29 de setembro de 1989. Recuperado de http://www.camara.gov.br/proposicoesWeb/fichad etramitacao?idProposicao $=20004$

Castilho, E. W. V. de. (2012). A eficácia invertida da internação involuntária. In Drogas e Cidadania: em debate (p. 35). Brasília: CFP

Colvero, L. de A., Ide, C. A. C., \& Rolim, M. A. (2004). Família e doença mental: a difícil convivência com a diferença. Revista Escola de Enfermagem da USP, 38(2), p. 198.

Conselho Federal de Psicologia. Comissão Nacional de Direitos Humanos. (2011). Relatório da 4a Inspeção nacional de Direitos Humanos: locais de internação para usuários de drogas. Recuperado de http://www.pol.org.br/pol/cms/pol/noticias/ noticia_111128_002.html.

Correia Junior, R., \& Ventura, C. A. A.(2013). As internações involuntárias de drogodependentes frente à legislação brasileira - uma análise em relação ao contexto histórico do tratamento de dependentes e as políticas higienistas e de profilaxia social. Revista Direitos Fundamentais \& Democracia, 13(13), 250-280.

Costa, A. A.(2012). Combate às drogas: Internação compulsória [Projeto de Pesquisa, Pós-Graduação Lato-Sensu da Escola da Magistratura do Estado do Rio de Janeiro]. Recuperado de http:/www.emerj.tjrj.jus.br/paginas/trabalhos conclusao/1semestre2012/trabalhos_12012/alicealbinocosta.pdf

Costa, I. I. (2013). Problematizações sobre a eficácia da internação compulsória no tratamento da drogadição. Debate Internação Compulsória - OAB/DF e CLDF, Brasília. Recuperado de http://www.unb.br/noticias/downloads/ATT00013.pdf

Dias, M. A. B. (2012) Políticas Públicas para o Combate às Drogas no Brasil [Monografia]. Recuperado de http://www.unipac. br/site/bb/tcc/tcc-0635f6ff3a902553a60464031931a8fe.pdf

França, G. L. (2012). Internação Compulsória do Dependente Químico: Violação do Direito de Liberdade ou Proteção do Direito à Vida?[Monografia]. Recuperado de http://intertemas.unitoledo.
br/revista/index.php/Juridica/article/viewArticle/3066

Freitas, C. C. (2010) Dependência Química: do tratamento não voluntário ao voluntário. Recuperado em 17 abril, 2014 de http:// www.abjt.org.br/index.php?id=99\&n=80.

Fortes, H.M. (2010, Dezembro). Tratamento compulsório e internações psiquiátricas. Revista Brasileira Saúde Maternal e Infantil, 10, 321-30. Recuperado de http://www.scielo.br/scielo. php?script $=$ sci arttext\&pid=S1519-38292010000600009

Goulart, D. C. S., Soares, A. C. N., Machado, A. R., \& Shera, W. (2013, Julho). Apoio intersetorial às famílias de dependentes de álcool e outras drogas. Sociedade em Debate, 19(2), 174-208. Recuperado de http://www.rsd.ucpel.tche.br/index.php/rsd/article/ view/958/740.

Instituto Crack nem Pensar. (n.d.). Política de redução de danos. Recuperado em 16 junho, 2014 de http://www.icnp.org.br/ perguntas.html.

Junior, N. C. (2013). Controvérsias a respeito da eficácia da lei antidrogas. Recuperado em 17 abril, 2014 de http://www.tjdft.jus. br/institucional/imprensa/artigos/2013/controversias-a-respeitoda-eficacia-da-lei-antidrogas-norberto-coutinho-junior

Lei n. 10.216, de 06 de abril de 2001(2001). Dispõe sobre a proteção e os direitos das pessoas portadoras de transtornos mentais e redireciona o modelo assistencial em saúde mental.

Lei n.11.343, de 23 de agosto de 2006 (2006). Institui o Sistema Nacional de Políticas Públicas sobre Drogas - Sisnad.

Leon, G. de. (2003). A comunidade terapêutica: teoria, modelo e método. São Paulo: Edições Loyola.

Maciel, A. L. (2013) Aspectos gerais sobre internação compulsória em saúde mental nos últimos 10 anos: revisão bibliográfica [Monografia]. Recuperado de http://repositorio. unesc.net/handle/1/1444.

Nappo, S. A., \& Sanchez, Z. V. D. M. (2008). Intervenção religiosa na recuperação de dependentes de drogas. Revista Saúde Pública, 42(2), 265-72.

Pinheiro, G. H. de A. (2012). O devido processo legal de internação psiquiátrica involuntária na ordem jurídica constitucional brasileira. Revista de Direito Sanitário, 12(3), 125-138.

Pinho, P. H. (2009). Os desafios na atenção aos usuários de álcool e outras drogas e a reabilitação psicossocial (Dissertação de mestrado, Escola de Enfermagem). Recuperada de http://www. teses.usp.br/teses/disponiveis/7/7134/tde-22062009-123744/

Pratta, E. M. M., \& Santos, M. A. dos. (2009) O processo saúde-doença e a dependência química: interfaces e evolução. Revista Psicologia: Teoria e pesquisa, 25(2), 203-211.

Portal Brasil.(2013). Crack, é possível vencer: enfrentar o crack; compromisso de todos. Recuperado de http://www2.brasil. gov.br/crackepossivelvencer/programa/cartilha

Rodrigues, E. (2012, Julho 23). Internação compulsória de viciados em drogas [Fórum]. Recuperado de http:// congressoemfoco.uol.com.br/opiniao/forum/internacaocompulsoria-de-viciados-em-drogas/

Secretaria Nacional de Políticas sobre Drogas [Senad]. (2010). Legislação e Políticas Públicas sobre Drogas. Recuperado de http:// www.fortaleza.ce.gov.br/sites/default/files/legislacao no brasil. pdf

Silva, C. R. (2013). Caracterização do perfil dos usuários que interromperam o acompanhamento em um Centro de Atenção Psicossocial álcool e outras drogas [Monografia]. Salvador. Recuperado de http://repositorio.ufba.br/ri/handle/ri/15127

Silveira, D. X., \& Silveira, E. D. X. da. (1999). Um guia para a família. Brasília: Senad.

Scisleski, A. C. C., Maraschin, C., \& da Silva, R. N. (2008). Manicômio em circuito: Os percursos dos jovens e a internação psiquiátrica. Caderno de saúde pública, 24(2), 342-352. Recuperado de http:/www.scielo.br/pdf/csp/v24n2/12.pdf

Takahashi, S. (2009). Controle de drogas, direitos humanos, e o direito ao mais alto padrão de saúde alcançável: de forma alguma questões simples. Revista Trimestral de Direitos Humanos, 31, 748 776. Recuperado de http://www.uniad.org.br/desenvolvimento/ images/stories/pdf/Projeto_MUSE_Traduo_-_final.pdf.

Vargas, B. (2012) Eliminação versus redução. In Drogas e Cidadania: em debate (p. 76). Brasília: CFP 
Ventura, C. A. A. (2013) As internações involuntárias de drogodependentes frente à legislação brasileira-uma análise em relação ao contexto histórico do tratamento de dependentes e as políticas higienistas e de profilaxia social. Revista Direitos Fundamentais \& Democracia, 13(13), 250-280. Recuperado de http://revistaeletronicardfd.unibrasil.com.br/index.php/rdfd/ article/view/352/320

Recebido: 21/08/2014

Última revisão: $27 / 01 / 2015$

Aceite final: 13/02/2015

Sobre os autores:

Viviana Rosa Reguera Ruiz - Curso de Psicologia, Universidade Católica Dom Bosco (UCDB).

E-mail: vivyh19@hotmail.com

Heitor Romero Marques - Licenciado em Ciências e Pedagogia [FUCMT], Especialista em Filosofia e Historia da Educação [FUCMT], Mestre em Educação - formação de professores [UCDB], Doutor em Desarrollo local y planteamineto territorial [UCM].

E-mail: heiroma@ucdb.br 